\title{
CRIANÇAS E ADOLESCENTES SEPARADOS OU DESACOMPANHADOS: UMA ANÁLISE SOBRE A RESOLUÇÃO CONJUNTA N. 1/2017 À LUZ DO DIREITO INTERNACIONAL
}

\author{
SEPARATED OR UNACCOMPANIED CHILDREN AND ADOLESCENTS: \\ AN ANAL YSIS OF THE JOINT RESOLUTION N. 1/2017 IN THE LIGHT OF INTERNATIONAL \\ LAW
}

\author{
iD Andressa Santana Arce \\ Universidade Federal de Mato Grosso do Sul - UFMS \\ Mestranda no Programa de Pós-Graduação em Direito da UFMS \\ Defensora Pública Federal \\ Campo Grande/MS. Brasil \\ andressa.arce@gmail.com \\ (iD) Ana Paula Martins Amaral \\ Universidade Federal de Mato Grosso do Sul - UFMS \\ Pós-doutora pela Universidade Federal de Santa Catarina - UFSC \\ Professora da Faculdade de Direito da UFMS \\ Campo Grande/MS. Brasil \\ ana.amaral@ufms.br
}

Resumo: O presente trabalho trata da proteção internacional assegurada às crianças e aos adolescentes, em contexto de migração internacional, que se encontram separados ou desacompanhados. Busca-se analisar, através do método dedutivo, se a Resolução Conjunta n. 1/2017 atende às diretrizes do Comentário Geral n. 6 do Comitê das Nações Unidas sobre Direitos das Crianças. A pesquisa é bibliográfica e documental. A investigação se justifica considerando o crescimento da migração infantil. Verificou-se que, no Brasil, coube à Resolução Conjunta tratar, com especificidade, dos procedimentos para a regularização migratória de crianças e adolescentes separados ou desacompanhados. A resolução tem plena aplicabilidade apenas em locais onde a Defensoria Pública da União esteja instalada ou presente, não eliminando, de forma cabal, as dificuldades para a regularização migratória desses indivíduos.

Palavras-chave: migração internacional; crianças desacompanhadas e separadas; Resolução Conjunta CONANDA.

\begin{abstract}
This paper addresses the international protection of children and adolescents, in the context of international migration, who are separated or unaccompanied. It aims to debate, trough deductive method, if the Joint Resolution n. 1/2017 matches the guidelines defined by the General Comment $n .6$ of the United Nations Committee on the Rights of the Child. The research is bibliographic and documental. The investigation is justified considering the growth of child migration. It was verified that, in Brazil, the procedures for migratory regularization of separated or unaccompanied children and adolescents are regulated, with specificity, by the Joint Resolution. The resolution only applies in places where Union`s Public Defender's offices are installed or in function, thus it does not eliminate, definitely, the difficulties concerning the migratory regularization of these persons.
\end{abstract}

Keywords: international migration; unaccompanied and separated children; Joint Resolution CONANDA. 
ARCE, Andressa Santana; AMARAL, Ana Paula Martins. Crianças e adolescentes separados ou desacompanhados: uma análise sobre a Resolução Conjunta n. 1/2017 à luz do direito internacional

\section{Introdução}

O relatório da Organização Internacional para as Migrações (OIM) World Migration de 2020, analisando os dados dos últimos anos, relaciona a migração às transformações econômicas, sociais, políticas e tecnológicas trazidas ou impostas pelos processos de globalização. Em relação aos últimos dois anos, o relatório destaca a ocorrência de grandes eventos causadores de deslocamento e migração, como os conflitos na Síria, no Iêmen, no Congo, na República Centro-Africana e no Sul do Sudão, a extrema violência contra o povo Rohingya em Mianmar e a severa instabilidade político-econômica na Venezuela.

A globalização - um termo que se sabe ser plurívoco - revela, assim, sua faceta cruel e geradora de exclusão quando se olha para os impactos que tem nas migrações internacionais, propondo, desta forma, grande desafio à proteção dos direitos humanos das pessoas mais vulneráveis.

De acordo com o relatório, em 2019, havia, no mundo, o total de 272 milhões de migrantes internacionais (3,5\% da população mundial).

O relatório do Alto Comissariado nas Nações Unidas para Refugiados (ACNUR) Global Trends sobre deslocamento forçado, de 2019, informa a existência de 26 milhões de refugiados no mundo, dos quais $40 \%$ são pessoas menores de 18 anos de idade.

Em 2005, o Comitê de Direitos da Criança da Organização das Nações Unidas (ONU) formulou o Comentário Geral n. 6 sobre o tratamento de crianças fora de seu país de origem desacompanhadas ou separadas, considerando o aumento de crianças nessas situações.

Com fundamento nos arts. 227 a 229 da Constituição Federal de 1988, na Convenção das ONU sobre os Direitos da Criança, promulgada no Brasil pelo Decreto 99.710/1990, na Convenção relativa ao Estatuto dos Refugiados, promulgada no Brasil pelo Decreto 50.215/1961, na Lei 9.474/1997, no Estatuto da Criança e do Adolescente e no referido Comentário Geral, o Conselho Nacional dos Direitos da Criança e do Adolescente (CONANDA), o Comitê Nacional para os Refugiados (CONARE), o Conselho Nacional de Imigração (CNIg) e a Defensoria Pública da União (DPU) editaram a Resolução Conjunta n. 1, em 9 de agosto de 2017, a fim de estabelecer procedimentos de identificação preliminar, atenção e proteção para crianças e adolescentes desacompanhados ou separados.

Essa resolução, conforme $\mathrm{o}$ art. $1^{\circ}$, se aplica às crianças e adolescentes de outras nacionalidades ou apátridas que se encontrem desacompanhados ou separados em ponto de fronteira. 
ARCE, Andressa Santana; AMARAL, Ana Paula Martins. Crianças e adolescentes separados ou desacompanhados: uma análise sobre a Resolução Conjunta n. 1/2017 à luz do direito internacional

Questiona-se, neste trabalho, se a Resolução Conjunta n. 1, em 9 de agosto de 2017, atende às diretrizes do Comentário Geral n. 6 do Comitê de Direitos da Criança da ONU. Assim, objetiva-se, através do método dedutivo, analisar se a Resolução Conjunta traz proteção jurídica suficiente para crianças e adolescentes separados ou desacompanhados no Brasil, à luz dos parâmetros de proteção internacional.

A pesquisa, quanto à forma, é qualitativa, quanto aos fins, descritiva e exploratória e, quanto aos meios, bibliográfica e documental.

Esta investigação se justifica, na medida em que documentos produzidos por organismos internacionais apontam que a migração internacional de crianças e adolescentes tem aumentado.

Na primeira parte do artigo, serão estabelecidos os conceitos referentes à migração internacional para os fins da presente pesquisa; após, será investigada a proteção internacional assegurada às crianças e aos adolescentes; então, será examinada a proteção internacional de crianças e adolescentes migrantes separados ou desacompanhados; por fim, serão analisados os procedimentos estabelecidos pela Resolução Conjunta CONANDA/CONARE/CNIg/DPU n. 1, de 2017, como ocorre sua aplicação, bem como sua adequação aos parâmetros de proteção internacional.

\section{Conceitos referentes à migração internacional para os fins do presente trabalho}

As migrações podem ser classificadas como forçadas ou voluntárias. As voluntárias são aquelas que ocorrem quando o indivíduo toma livremente a decisão de migrar, sem intervenção de um fator externo, já as forçadas acontecem quando a vontade de se deslocar é mínima ou inexistente, sendo o refúgio a situação clássica de migração forçada (JUBILUT; APOLINÁRIO, 2010, p. 281).

Refugiado, segundo a Convenção relativa ao Estatuto dos Refugiados de 1951 e o Protocolo de 1967, é o indivíduo que, por temer ser perseguido por motivos de raça, religião, nacionalidade, grupo social ou opiniões políticas, se encontra fora se seu país de nacionalidade ou de residência habitual e não pode ou, em virtude desse temor, não quer a ele retornar. A Declaração de Cartagena de 1984, adotada pelo Colóquio sobre Proteção Internacional dos Refugiados na América Central, México e Panamá ([2001?]), realizado na Colômbia, também reconhece como refugiadas as pessoas que tenham sofrido deslocamento forçado em razão de graves violações a direitos humanos. Este conceito ampliado de refugiado é o adotado no Brasil.

Neste trabalho, quando se fizer menção à migração internacional, sem especificação, deverão ser considerados os descolamentos internacionais forçados e não forçados. Será 
ARCE, Andressa Santana; AMARAL, Ana Paula Martins. Crianças e adolescentes separados ou desacompanhados: uma análise sobre a Resolução Conjunta n. 1/2017 à luz do direito internacional

utilizado migrante tanto para aqueles em situação de migração forçada ou voluntária, realizando-se a devida distinção quando for necessário.

\section{A proteção de crianças e adolescentes no Direito Internacional}

Bobbio (2004), afirmando o caráter histórico dos direitos humanos - cuja origem está nas reivindicações da sociedade ao longo do tempo -, expõe que a partir dos séculos XVII e XVIII, esses direitos passaram pelos processos de positivação, generalização, internacionalização e especificação da proteção do indivíduo. Ele sustenta que o processo de multiplicação por especificação ocorreu principalmente em relação aos direitos sociais:

\footnotetext{
Essa universalidade (ou indistinção, ou não discriminação) na atribuição e no eventual gozo dos direitos de liberdade não vale para os direitos sociais, e nem mesmo para os direitos políticos, diante dos quais os indivíduos são iguais só genericamente, mas não especificamente. Com relação aos direitos políticos e aos direitos sociais, existem diferenças de indivíduo para indivíduo, ou melhor, de grupos de indivíduos para grupos de indivíduos, diferenças que são até agora (e o são intrinsecamente) relevantes (BOBBIO, 2004, p. 78).
}

Com o reconhecimento dos direitos sociais, transcendeu-se a figura do homem genérico ou abstrato. Surgiram, então, novos personagens nas declarações de direitos humanos: a mulher, a criança, o idoso, a pessoa com deficiência etc. (BOBBIO, 2004, p. 78).

Segundo Isabelle Dias Carneiro Santos (2018, p. 98), a criança - aqui compreendida como a pessoa com idade inferior a 18 anos - somente ganhou uma certa importância e proteção jurídica a partir do século XVIII. Na esfera internacional, a Declaração da Liga sobre os Direitos das Crianças de 1924 foi o primeiro documento de proteção a ser produzido, o que se deu no âmbito da Liga das Nações, a qual foi criada em 1919 pelo Tratado de Versalhes, logo após a Primeira Guerra Mundial. Essa Declaração da Liga, no entanto, colocava a criança em uma situação passiva, tratando-a como mero objeto de proteção (SANTOS, 2018, p. 98).

Após a consolidação da Declaração Universal de Direitos Humanos de 1948 - que reconhece a necessidade de proteção da infância em seu art. 25 -, foi elaborada, em 1959, a Declaração Universal sobre Direito das Crianças - criada não com força de tratado internacional, mas com valor jurídico de recomendação -, desta vez, tratando-as, não como objetos de proteção, mas, sim, como sujeitos de direitos (SANTOS, 2008, p. 98).

Sobre a Declaração Universal sobre Direito das Crianças de 1959, Amaral (2012) afirma que o documento serviu de base moral e teórica para o sistema de proteção de direitos da criança e trouxe grande avanço ao prever diversos direitos a serem assegurados às crianças pelos Estados: 
ARCE, Andressa Santana; AMARAL, Ana Paula Martins. Crianças e adolescentes separados ou desacompanhados: uma análise sobre a Resolução Conjunta n. 1/2017 à luz do direito internacional

\begin{abstract}
A Declaração inovou ao estabelecer direitos às crianças, nas diversas esferas em um único documento: direitos civis (como direito à igualdade, sem distinção de raça, religião ou nacionalidade), políticos (direito a um nome e a uma nacionalidade), direitos sociais, econômicos e culturais (Direito à alimentação, moradia e assistência médica adequadas para a criança e a mãe) Direito à educação gratuita e ao lazer; Direito a especial proteção para o seu desenvolvimento físico, mental e social. Fala em dar máxima prioridade aos direitos da criança e lembra que a criança necessita de amor e compreensão para o desenvolvimento pleno e harmonioso de sua personalidade (AMARAL, 2012, p. 73).
\end{abstract}

Um conjunto sistematizado de normas específicas sobre a proteção de direitos das crianças e adolescentes, pautado em seu melhor interesse, com natureza vinculante para os Estados signatários, somente foi formulada no âmbito das Nações Unidas em 1989, com o advento da Convenção sobre os Direitos da Criança, a qual entrou em vigor internacional em 2 de setembro de 1990, tendo sido promulgada no Brasil pelo Decreto 99.710/1990.

De acordo com o Amaral (2012), a Convenção sobre Direitos das Crianças de 1989 inova ao estabelecer que os Estados signatários devem alicerçar suas ações administrativas e legislativas nos princípios do maior interesse da criança e da integralidade de seu desenvolvimento físico, mental, moral e social. Importante destacar que os seus dois protocolos adicionais referem-se à situação de crianças em extrema vulnerabilidade: sobre o envolvimento de crianças em conflitos armados; e a respeito da prevenção, repressão e punição do tráfico de pessoas, especialmente de mulheres e crianças (AMARAL, 2012, p. 84).

A Convenção sobre Direitos das Crianças, em seu art. $1^{\circ}$, considera como criança todo ser humano com menos de 18 anos de idade e consagra no item 1 do art. $3^{\circ}$ o princípio do interesse maior da criança: "Todas as ações relativas às crianças, levadas a efeito por instituições públicas ou privadas de bem estar social, tribunais, autoridades administrativas ou órgãos legislativos, devem considerar, primordialmente, o interesse maior da criança" (ONU, [2017?], não paginado).

No art. 12, tem-se que os Estados devem assegurar à criança que for capaz de formular seus próprios juízos o direito de se expressar livremente, inclusive nos processos judiciais ou administrativos em que tenha interesse, devendo sua opinião ser levada em conta, sem deixar de se ter em vista sua idade e maturidade.

No que tange às crianças refugiadas, a Convenção traz a seguinte proteção: 
ARCE, Andressa Santana; AMARAL, Ana Paula Martins. Crianças e adolescentes separados ou desacompanhados: uma análise sobre a Resolução Conjunta n. 1/2017 à luz do direito internacional

\begin{abstract}
Artigo 22
1. Os Estados Partes adotarão medidas pertinentes para assegurar que a criança que tente obter a condição de refugiada, ou que seja considerada como refugiada de acordo com o direito e os procedimentos internacionais ou internos aplicáveis, receba, tanto no caso de estar sozinha como acompanhada por seus pais ou por qualquer outra pessoa, a proteção e a assistência humanitária adequadas a fim de que possa usufruir dos direitos enunciados na presente convenção e em outros instrumentos internacionais de direitos humanos ou de caráter humanitário dos quais os citados Estados sejam parte.

2. Para tanto, os Estados Partes cooperarão, da maneira como julgarem apropriada, com todos os esforços das Nações Unidas e demais organizações intergovernamentais competentes, ou organizações não-governamentais que cooperem com as Nações Unidas, no sentido de proteger e ajudar a criança refugiada, e de localizar seus pais ou outros membros de sua família a fim de obter informações necessárias que permitam sua reunião com a família. Quando não for possível localizar nenhum dos pais ou membros da família, será concedida à criança a mesma proteção outorgada a qualquer outra criança privada permanente ou temporariamente de seu ambiente familiar, seja qual for o motivo, conforme o estabelecido na presente convenção (ONU, [2017?], não paginado, grifo nosso).
\end{abstract}

O art. 22 da Convenção sobre os Direitos das Crianças reconhece a vulnerabilidade da criança em situação de migração forçada e lhe garante, expressamente, o direito ao acesso aos procedimentos para fins de reconhecimento da condição de refugiada, ainda que esteja sozinha ou com adulto que não seja um de seus pais, bem como a proteção e a assistência humanitária para que possa usufruir dos demais direitos previstos no documento e em outros instrumentos internacionais.

Não há na Convenção previsão semelhante para as crianças em situação de migração não forçada. O que se tem a respeito é o dever de o Estado atender de forma "positiva, humanitária e rápida" toda solicitação apresentada por uma criança para ingressar no país com vistas à reunião da família, de acordo com o art. 10, item 1, regra aplicável tanto a migrantes voluntário quanto a refugiados.

Assim, a Convenção, ao tratar da migração internacional de crianças e adolescentes, trouxe proteção específica apenas para aqueles que visem ao reconhecimento da condição de refugiados.

3 Crianças e adolescentes separados ou desacompanhados e o Comentário Geral n. 6 do Comitê de Direitos da Criança

Em 2005, o Comitê de Direitos da Criança - doravante, "o Comitê" -, cujo mandato está limitado à função de supervisão em relação à Convenção de Direito das Crianças, conforme o art. 43 da Convenção de Direitos das Crianças, editou o Comentário Geral n. 6 (CRC, 2005) sobre o tratamento de crianças fora se seu país de origem desacompanhadas e separadas, considerando a observação de aumento de crianças nessas situações, em decorrência de 
perseguição dos pais ou da criança, tráfico de pessoas, conflitos internacionais, guerras civis e busca por melhores oportunidades de vida.

O objetivo do Comentário Geral consiste em chamar atenção para a vulnerabilidade das crianças separadas e desacompanhadas e estabelecer parâmetros de proteção a esses indivíduos com base na Convenção de Direitos das Crianças. Destacam-se os vários riscos a que se sujeitam as crianças nessas situações assinalados pelo Comitê:

3. The issuing of the general comment is further motivated by the Committee's identification of a number of protection gaps in the treatment of such children, including the following: unaccompanied and separated children face greater risks of, inter alia, sexual exploitation and abuse, military recruitment, child labour (including for their foster families) and detention. They are often discriminated against and denied access to food, shelter, housing, health services and education. Unaccompanied and separated girls are at particular risk of gender-based violence, including domestic violence. In some situations, such children have no access to proper and appropriate identification, registration, age assessment, documentation, family tracing, guardianship systems or legal advice. In many countries, unaccompanied and separated children are routinely denied entry to or detained by border or immigration officials. In other cases they are admitted but are denied access to asylum procedures or their asylum claims are not handled in an age and gendersensitive manner. Some countries prohibit separated children who are recognized as refugees from applying for family reunification; others permit reunification but impose conditions so restrictive as to make it virtually impossible to achieve. Many such children are granted only temporary status, which ends when they turn 18 , and there are few effective return programmes ${ }^{1}$ (CRC, 2005, p. 5).

\section{No Comentário Geral, o Comitê adota as seguintes definições de crianças}

desacompanhadas e separadas:

7. "Unaccompanied children" (also called unaccompanied minors) are children, as defined in article 1 of the Convention, who have been separated from both parents and other relatives and are not being cared for by an adult who, by law or custom, is responsible for doing so.

8. "Separated children" are children, as defined in article 1 of the Convention, who have been separated from both parents, or from their previous legal or customary primary caregiver, but not necessarily from other relatives. These may, therefore, include children accompanied by other adult family members ${ }^{2}$ (CRC, 2005, p. 6).

\footnotetext{
1 “3. A edição do comentário geral é ainda motivada pela identificação, pelo Comitê, de um número de lacunas na proteção em relação a essas crianças, incluindo as seguintes: crianças separadas e desacompanhadas são mais suscetíveis aos riscos de, inter alia, exploração e abuso sexual, recrutamento militar, trabalho infantil (incluindo para as famílias adotivas) e detenção. Elas são frequentemente discriminadas e têm acesso à comida, a abrigo, à moradia, a serviços de saúde e à educação negado. Meninas separadas e desacompanhadas sofrem, particularmente, risco de violência de gênero, incluindo violência doméstica. Em algumas situações, essas crianças não têm acesso à identificação adequada, ao registo, à avaliação etária, à documentação, à busca de familiares, a sistemas de guarda ou assistência jurídica. Em muitos países, crianças separadas e desacompanhadas têm, rotineiramente, negada a entrada ou são detidas pela fronteira ou por agentes oficiais de imigração. Em outros casos, elas são admitidas, mas lhes é negado acesso ao procedimento de asilo ou suas solicitações de asilo não são analisadas de forma sensível à idade e ao gênero. Alguns países proíbem crianças separadas que são reconhecidas como refugiadas de pedir reunificação familiar; outros permitem a reunificação, mas impõem condições tão restritivas para a fim de torná-la inviável. A muitas dessas crianças é concedido apenas status temporário, que acaba quando atingem 18, e há poucos programas e retorno efe tivos" (CRC, 2005, p. 5, tradução livre).

2 “7. 'Crianças desacompanhadas' (também chamadas de menores desacompanhados) são crianças, conforme definição do artigo 1 da Convenção, que foram separadas de ambos os pais e de outros parentes e não estão sob os cuidados de um adulto que, por lei ou costume, seja por elas responsável. 8. 'Crianças separadas' são crianças, conforme definição do artigo 1 da Convenção, que foram separadas de ambos os pais ou de seu prévio responsável legal ou costumeiro, mas não necessariamente de outros parentes. Estas podem, pois, incluir crianças acompanhadas de outros membros adulto da família” (COMMITTEE ON THE RIGHTS OF THE CHILD, 2005, p. 6, tradução livre).
} 
ARCE, Andressa Santana; AMARAL, Ana Paula Martins. Crianças e adolescentes separados ou desacompanhados: uma análise sobre a Resolução Conjunta n. 1/2017 à luz do direito internacional

O Comitê ressalta que a atuação dos Estados, diante dessas situações, deve ser guiada, durante todo o ciclo de deslocamento da criança ou do adolescente, pelos princípios da não discriminação, do melhor interesse da criança na busca de solução a curto ou longo prazo, da confidencialidade e do non-refoulement. Frisa, ademais, a necessidade de os Estados, em atenção ao art. $6^{\circ}$ da Convenção - o qual se refere ao direito à vida e ao desenvolvimento -, adotarem as providências necessárias para fins de proteção das crianças e adolescentes desacompanhados contra violência e exploração e, ainda, à luz do art. 12 da Convenção, levarem em conta as opiniões e desejos desses indivíduos, devendo informá-los de seus direitos.

Em relação ao princípio do non-refoulement, cabe notar que se trata de pedra angular do Direito Internacional dos Refugiados, cuja previsão se encontra no art. 33 da Convenção relativa ao Estatuto dos Refugiados de 1951:

Art. 33 - Proibição de expulsão ou de rechaço

1. Nenhum dos Estados Contratantes expulsará ou rechaçará, de maneira alguma, um refugiado para as fronteiras dos territórios em que a sua vida ou a sua liberdade seja ameaçada em virtude da sua raça, da sua religião, da sua nacionalidade, do grupo social a que pertence ou das suas opiniões políticas (ONU, [2001?], não paginado).

Salienta o Comitê que as crianças e os adolescentes separados ou desacompanhados que forem reconhecidos como refugiados gozam não só dos direitos previstos na Convenção relativa ao Estatuto dos Refugiados, mas também dos direitos humanos garantidos às crianças e adolescentes no país receptor.

Observa-se, no Comentário Geral, que o Comitê entende imprescindível a implementação de um processo de avaliação inicial da situação da criança ou do adolescente separado ou desacompanhado, o qual deve incluir: sua imediata identificação; a realização de entrevista a ser conduzida por profissional qualificado, em um ambiente seguro e amigável, para a coleta de dados pessoais, incluindo histórico social e informações sobre os pais e outros parentes; e a indicação, sempre que possível, das razões que levaram a criança ou o adolescente a estar separado ou desacompanhados, de suas vulnerabilidades específicas e de informações que possam determinar a aplicação da Convenção relativa ao Estatuto dos Refugiados de 1951.

O Comitê também sustenta a necessidade de os Estados adotarem as medidas cabíveis, de acordo com seus ordenamentos jurídicos internos, com o intuito de assegurar devida representação legal à criança ou ao adolescente, mediante nomeação de guadian ou adviser em tradução livre, guardião ou conselheiro. No caso de crianças e adolescentes separados, a guarda deverá ser concedida, prioritariamente, ao familiar adulto que estiver em sua companhia, exceto se isso não atender ao melhor interesse da criança ou do adolescente. Se a criança ou o 
ARCE, Andressa Santana; AMARAL, Ana Paula Martins. Crianças e adolescentes separados ou desacompanhados: uma análise sobre a Resolução Conjunta n. 1/2017 à luz do direito internacional

adolescente for solicitante de refúgio ou parte em processo administrativo ou judicial, deverá ser-lhe garantida assistência jurídica.

Eis o que se tem no Comentário Geral a respeito da representação legal dessas crianças e adolescentes em situação de emergência de larga escala:

38. In large-scale emergencies, where it will be difficult to establish guardianship arrangements on an individual basis, the rights and best interests of separated children should be safeguarded and promoted by States and organizations working on behalf of these children ${ }^{3}$ (CRC, 2005, p. 13).

O Comentário Geral versa, ainda, sobre os direitos de crianças e adolescentes separados ou desacompanhados ao cuidado e a uma acomodação adequada - não devendo, como regra geral, serem privados de liberdade -, à educação, a um padrão de vida adequado e ao acesso a serviços de saúde, bem como sobre a adoção de medidas preventivas contra tráfico de pessoas, toda forma de exploração, abuso e violência, recrutamento militar e privação da liberdade. Aponta, por fim, que, no que tange a esse grupo vulnerável específico, devem ser buscadas soluções duradouras, tais como a reunião familiar, o retorno ao país de origem, a integração local, a adoção internacional ou o reassentamento em um terceiro país.

Diante de todo o exposto, extrai-se que o Comitê de Direitos da Criança, ao editar o Comentário Geral n. 6, buscou estabelecer diretrizes para que a proteção das crianças e adolescentes separadas ou desacompanhadas, em contexto de migração internacional, ocorra de forma harmoniosa com o Direito Internacional dos Refugiados e com o Direito Internacional de Direitos Humanos.

Segundo o relatório da OIM World Migration de 2020 (IOM, 2020), embora os dados a esse respeito possam ser considerados incompletos, é largamente aceita a afirmação de que migração de crianças e adolescentes tem aumentado. O relatório cita, além do Comentário Geral n. 6, o Comentário Geral Conjunto n. 3, de 2017, do Comitê para a Proteção dos Trabalhadores Migrantes e dos Membros de Suas Famílias e n. 22, de 2017, do Comitê sobre Direitos das Crianças, sobre os princípios referentes aos direitos humanos das crianças no contexto da migração internacional, documentos que ressaltam a necessidade de proteção especial - a ser efetivada pelos Estados - para as crianças e adolescentes migrantes internacionais.

A OIM destaca, no entanto, que a implementação dessas recomendações não tem sido satisfatória:

\footnotetext{
3 “38. Em emergências de larga escala, em que será difícil estabelecer os arranjos de guarda de forma individual, os direitos e o melhor interesse das crianças separadas devem ser resguardados e promovidos pelos Estados e organizações trabalhando em favor dessas crianças" (CRC, 2005, p. 13, tradução livre).
} 
ARCE, Andressa Santana; AMARAL, Ana Paula Martins. Crianças e adolescentes separados ou desacompanhados: uma análise sobre a Resolução Conjunta n. 1/2017 à luz do direito internacional

However, effective implementation of these recommendations has been mixed. All the documents just referenced stress the imperative to issue birth registration and concomitant proof of identity for all children in the territory, because these documents provide critical tools for reducing statelessness, exploitation and abuse of child migrants, and for increasing access to State facilities such as health care and education. But many groups of migrant and refugee children continue to lack these documents. They include Syrians born in exile, and Rohingya in Myanmar and abroad. Integration of migrant children outside of family care within the national childcare or child protection agency is still not the norm. Research has identified a policy and practice gap in the protection and support apparatus related to the transition to adulthood, with obvious implications for both mental health and wellbeing. There are, however, some examples of good practice, such as Italy and Turkey ${ }^{4}$ (IOM, 2020, p. 245).

No âmbito no sistema americano, merece destaque o Parecer Consultivo OC-21/14, de 19 de agosto de 2014, sobre "infância migrante” da Corte Interamericana de Direitos Humanos, o qual reconhece a Convenção sobre Direitos das Crianças como o tratado internacional de maior vocação de universalidade da Convenção sobre Direitos das Crianças e reafirma a obrigação dos Estados no sentido de priorizar os direitos das crianças, objetivando sua proteção e seu desenvolvimento integral, independentemente de sua nacionalidade ou de seu status migratório (CIDH, 2014).

4 A Resolução Conjunta CONANDA/CONARE/CNIG/DPU n. 1/2017 e a proteção de crianças e adolescentes migrantes separados ou desacompanhados no Brasil

Com o intuito de estabelecer procedimentos de identificação preliminar, atenção e proteção para crianças e adolescentes desacompanhados ou separados, o CONANDA, o CONARE, o CNIg e a DPU editaram, à luz da Convenção sobre os Direitos da Criança, da Convenção relativa ao Estatuto dos Refugiados e do Comentário Geral n. 6 do Comitê de Direitos da Criança, a Resolução Conjunta n. 1, em 9 de agosto de 2017. O documento invoca como fundamento, no direito interno, os arts. 227 a 229 da Constituição Federal de 1988, a Lei 9.474/1997 (Estatuto dos Refugiados) e o Estatuto da Criança e do Adolescente.

Ao CONANDA, de acordo com o art. $2^{\circ}$ da Lei 8.242/1991, compete elaborar normas gerais da política de atendimento aos direitos das crianças e dos adolescentes (inciso I). O CNIg foi criado pela Lei 6.815/1980 (Estatuto do Estrangeiro) e tem suas atribuições previstas no Decreto 9.873/2019 - que, por sua vez, revogou o Decreto 840/1993, também sobre o

\footnotetext{
4 "No entanto, a implementação efetiva dessas recomendações tem sido variada. Todos os documentos referidos destacam a necessidade de realizar registro de nascimento prova concomitante de identidade para todas as crianças no território, porque estes documentos propiciam mecanismos importantes para a redução de apatridia, exploração e abuso da criança migrante e o aumento do acesso a serviços públicos, como os de saúde e educação. Mas muitos grupos de crianças migrantes e refugiadas continuam sem esses documentos. Entre eles, os sírios nascidos no exílio, os Rohingya, em Myanmar e em outros países. A integração das crianças migrantes fora do cuidado com a família dentro na agência nacional de cuidado e proteção à criança ainda não é norma. Pesquisa identificou lacuna entre política e prática na proteção e atenção referente à transição para a idade adulta, com implicações óbvias tanto para a saúde mental quanto para o bem-estar. Há, contudo, alguns exemplos de boa prática, como a Itália e a Turquia" (INTERNATIONAL ORGANIZATION FOR MIGRATION, 2020, p. 245, tradução livre).
} 
ARCE, Andressa Santana; AMARAL, Ana Paula Martins. Crianças e adolescentes separados ou desacompanhados: uma análise sobre a Resolução Conjunta n. 1/2017 à luz do direito internacional

funcionamento do $\mathrm{CNIg}$-, entre elas, emitir resolução com caráter normativo $\left(\operatorname{art.} 2^{\circ}\right.$ ). O CONARE, conforme os arts. 11 e 12 da Lei 9.474/1997 (Estatuto do Refugiado), é um órgão de deliberação coletiva com atribuição para aprovar instruções normativas para fins de aplicação da lei que o prevê (art. 12, V). Quanto à DPU, nos termos do art. 8º, I, da Lei Complementar 80/1994, o Defensor-Público Geral tem atribuição para dirigir o órgão, coordenar suas atividades e orientar sua atuação. Por força desses dispositivos, a Resolução Conjunta n. 1/2017 tem natureza vinculante, não se tratando de mera recomendação.

Importante destacar que essa Resolução foi editada durante a vacatio legis da Lei 13.445/2017 (Lei de Migração), que revogou a Lei 6.815/1980 (Estatuto do Estrangeiro) e abandonou, conforme explicam Amaral e Costa (2017) a lógica da segurança nacional, em que o imigrante era tido como um inimigo em potencial, para tratar a migração como fato social a ser abordado pela ótica de direitos humanos.

A Constituição Federal de 1988, em seu art. 227 - com a redação dada pela Emenda Constitucional 65/2010 -, estabelece como dever do Estado, da família e da sociedade assegurar às crianças e aos adolescentes, com absoluta prioridade, uma série de direitos - à vida, à saúde, à educação, à dignidade, à convivência familiar e comunitária etc. -, “" [...] além de colocá-los a salvo de toda forma de negligência, discriminação, exploração, violência, crueldade e opressão" (BRASIL, 2020a, não paginado).

A Lei 8.069/1990 (Estatuto da Criança e do Adolescente) reafirma o disposto na Constituição e prevê que "a criança e o adolescente gozam de todos os direitos fundamentais inerentes à pessoa humana $[\ldots]^{\prime \prime}\left(\operatorname{art.} 3^{\circ}\right.$, caput $)$ e ainda:

\begin{abstract}
Art. $3^{\circ}[\ldots]$
Parágrafo único. Os direitos enunciados nesta Lei aplicam-se a todas as crianças e adolescentes, sem discriminação de nascimento, situação familiar, idade, sexo, raça, etnia ou cor, religião ou crença, deficiência, condição pessoal de desenvolvimento e aprendizagem, condição econômica, ambiente social, região e local de moradia ou outra condição que diferencie as pessoas, as famílias ou a comunidade em que vivem. (incluído pela Lei no 13.257, de 2016) (BRASIL, 2019b, não paginado).
\end{abstract}

Em momento algum, a Lei 8.069/1990 dispõe, de forma específica, sobre crianças e adolescentes separados ou desacompanhados em contexto de migração internacional.

A Lei 9.474/1997 (Estatuto dos Refugiados) define os mecanismos para a implementação da Convenção Relativa ao Estatuto dos Refugiados de 1951, estabelecendo o procedimento o reconhecimento do status de refugiado no Brasil. Adota o conceito mais amplo de refugiado, conforme proposto pela Declaração de Cartagena de 1984, consoante se pode observar em seu art. $1^{\circ}$. Não traz previsão específica sobre os direitos de crianças e adolescentes separados ou desacompanhados. 
ARCE, Andressa Santana; AMARAL, Ana Paula Martins. Crianças e adolescentes separados ou desacompanhados: uma análise sobre a Resolução Conjunta n. 1/2017 à luz do direito internacional

Cabe notar que a Lei de Migração, no art. 40, caput e inciso I, prevê a admissão excepcional no país de criança ou adolescente desacompanhado de responsável legal, “[...] independentemente do documento de viagem que portar, hipótese em que haverá imediato encaminhamento ao Conselho Tutelar ou, em caso de necessidade, a instituição indicada pela autoridade competente" (BRASIL, [2017b], não paginado).

Constata-se, pois, que a Resolução Conjunta CONANDA/CONARE/CNIg/DPU n. 1/2017 é o ato normativo em vigor que trata com especificidade sobre os procedimentos de identificação, proteção e representação, para fins de regularização migratória, de crianças e adolescentes separados desacompanhados. Não se ignora que a Portaria 197 do Ministério da Justiça, de 6 de março de 2019, também dispõe sobre a regularização migratória de crianças e adolescentes separados ou desacompanhados, porém este ato se refere tão somente aos trâmites para requerimento de autorização de residência e emissão de Carteira de Registro Nacional Migratório, determinando que o reconhecimento da condição de criança ou adolescentes separado ou desacompanhado, sem estabelecer os procedimentos para tanto, poderá ser feito pela DPU ou por decisão judicial.

A Resolução Conjunta, nos termos de seu art. $1^{\circ}$, se aplica às crianças e adolescentes de outras nacionalidade ou apátridas que se encontrem desacompanhados ou separados em ponto de fronteira e adota as mesmas definições de criança ou adolescente desacompanhado ou separado que foram utilizadas pelo Comitê de Direitos da Criança no Comentário Geral n. 6:

\footnotetext{
Art. $1^{\circ}[\ldots]$

I - Criança ou adolescente desacompanhado: aquele que não possui nenhuma pessoa adulta acompanhando-lhe no seu ingresso em território nacional;

II - Criança ou adolescente separado: aquele que está acompanhado por uma pessoa adulta que não é o responsável legal que detenha poder familiar, no seu ingresso em território brasileiro (BRASIL, 2017a, não paginado).
}

É questionável a aplicabilidade da Resolução Conjunta apenas às crianças e adolescentes que estejam em ponto de fronteira, na medida em que não se pode admitir que fiquem sem atendimento os indivíduos que, por qualquer motivo, passarem desse ponto, ingressando, assim, no Brasil, sem ter tido acesso aos procedimentos cabíveis para fins de regularização migratória.

Consoante o art. $9^{\circ}$ da Resolução Conjunta, a autoridade de fronteira que receber criança ou adolescente desacompanhado ou separado deverá registrar a ocorrência, realizar-lhe a identificação biográfica e a biométrica, proceder ao registro de entrada no controle migratório e notificar a DPU, o Conselho Tutelar, bem como o Juízo e a Promotoria da Infância e Juventude. 
ARCE, Andressa Santana; AMARAL, Ana Paula Martins. Crianças e adolescentes separados ou desacompanhados: uma análise sobre a Resolução Conjunta n. 1/2017 à luz do direito internacional

Conforme o art. 10 do ato normativo, a entrevista individual da criança ou do adolescente e a análise da medida proteção adequada ao caso competirá à DPU. Ao Defensor Público Federal caberá realizar entrevista com a criança ou adolescente, a qual deverá ser conduzida de forma sensível à sua idade, identidade de gênero, entre outras peculiaridades.

No art. 12, a Resolução Conjunta prescreve que a DPU será responsável pelos pedidos de regularização migratória das crianças e adolescentes separados ou desacompanhados, pela solicitação dos documentos pertinentes e pelo preenchimento o formulário para análise de proteção constante do Anexo I do ato normativo. Compete-lhe, ainda, acompanhá-los nos procedimentos subsequentes à identificação preliminar.

O art. 13 estabelece que o Defensor Público Federal responsável pelos pedidos de regularização migratória deverá indicar no formulário para análise de proteção a possibilidade de:

\footnotetext{
Art. 13. [...]

I - retorno à convivência familiar, conforme parâmetros de proteção integral e atenção ao interesse superior da criança e do adolescente;

II - medida de proteção por reunião familiar;

III -proteção como vítima de tráfico de pessoas;

IV - outra medida de proteção migratória, ou proteção como refugiado ou apátrida, conforme a legislação em vigor.

Parágrafo único A criança ou adolescente desacompanhados ou separados deverão ser consultados sobre as possibilidades de residência e acolhimento, assegurado seu protagonismo (BRASIL, 2017a, não paginado).
}

O formulário para análise de proteção tem campos para que se informem dados do Defensor Público Federal que está realizando a entrevista, dados da criança ou do adolescente, as circunstâncias de entrada no Brasil, os motivos que levaram a criança ou o adolescente a deixar seu país de origem ou residência, se houve ajuda de alguém para ingressar no Brasil, se ingressou acompanhada ou acompanhado de alguém, se tem intenção de retornar ao seu país de origem ou residência, se tem familiares no Brasil ou em seu país de origem ou residência, as medidas de proteção aplicáveis - como o retorno à convivência familiar, regularização migratória ou a solicitação de refúgio, por exemplo -, entre outras informações relevantes para a análise do caso.

No art. 16, lê-se o seguinte:

Art. 16. O Defensor Público da União [o termo correto é Defensor Público Federal, de acordo com a Lei Complementar 80/1994] terá competência também para representar, para fins de apresentação de pedidos de regularização migratória, solicitação de documentos e demais atos de proteção e garantia de direitos, as crianças e adolescentes desacompanhados ou separados que se encontrarem em território de jurisdição brasileira, aplicando-se para essas hipóteses, no que couber, os termos desta Resolução (BRASIL, 2017a, não paginado). 
ARCE, Andressa Santana; AMARAL, Ana Paula Martins. Crianças e adolescentes separados ou desacompanhados: uma análise sobre a Resolução Conjunta n. 1/2017 à luz do direito internacional

Quanto à natureza dessa representação prevista no art. 16, o Manual de Procedimento e Peças da Coordenação de Migrações e Refúgio da DPU em São Paulo, elaborado pela DPU, em 2018, em parceria com a OIM, esclarece que

[...] não configura hipótese de tutela ou curatela material. Trata-se de forma de curadoria específica para representação legal em processos de regularização migratória (atualmente, apenas solicitação de refúgio) [à época, ainda não havia sido devidamente regulamentada a Lei de Migração] para crianças e adolescentes. Nesse caso, a DPU atua independentemente de análise de hipossuficiência econômica (DPU; OIM, 2018, p. 66).

Verifica-se que a Resolução Conjunta atribuiu à DPU papel fundamental no processo de identificação a proteção adequada à criança e ao adolescente que ingressam no Brasil desacompanhados ou separados de seus pais ou responsáveis, pois, além de ficar incumbida da entrevista e do preenchimento do formulário de proteção, poderá representá-los - caso não seja identificado nenhum outro adulto, com vínculo familiar, que possa se responsabilizar por isso - para fins de apresentação de pedido de regularização migratória, a qual resultará na obtenção de documentação brasileira que possibilitará - ou facilitará - o acesso a direitos.

Levando-se em conta as recomendações constantes Comentário Geral n. 6 do Comitê de Direitos da Criança a respeito da representação de crianças e adolescentes separados ou desacompanhados, é possível inferir que a DPU desempenha dupla atribuição: além de promover a assistência jurídica gratuita, atuando, portanto, nos processos judiciais e administrativos de sua atribuição concernentes à criança ou ao adolescente, figura como representante legal, no exercício de curadoria sui generis, da criança ou do adolescente nos processos de regularização migratória.

O problema dessa opção feita pelos órgãos que editaram a Resolução Conjunta está na deficiência estrutural da DPU. Por possuir poucos membros e sérias limitações orçamentárias, o órgão não tem unidades suficientes para o atendimento do público alvo da Resolução Conjunta. Segundo o documento "Assistência Jurídica Integral e Gratuita no Brasil: um panorama da atuação da Defensoria Pública da União”, de 2018, elaborado pelo próprio órgão, havia o total de 601 Defensores Púbicos Federais em todo o Brasil e 71 unidades instaladas:

Vale ressaltar que os órgãos de atuação da DPU atualmente instalados cobrem um total de 1.837 municípios, e a população potencialmente atendida (pessoas acima de dez anos de idade e com renda até dois salários mínimos) contida nesses municípios é de 42.197.080 pessoas. No entanto, o país possui 5.565 municípios e 75.073.409 cidadãos potencialmente a serem atendidos pela DPU. Desse modo, a Defensoria Pública da União abrange apenas cerca de $33 \%$ dos municípios brasileiros e a população alvo sem cobertura da DPU corresponde a 44\%. (DPU, 2018, p. 57). 
ARCE, Andressa Santana; AMARAL, Ana Paula Martins. Crianças e adolescentes separados ou desacompanhados: uma análise sobre a Resolução Conjunta n. 1/2017 à luz do direito internacional

Logo, tendo em conta os parâmetros definidos no Comentário Geral n. 6 do Comitê de Direitos da Criança, pode-se afirmar que a Resolução Conjunta não assegura proteção suficientemente abrangente para o grupo vulnerável em questão.

Por outro lado, cumpre salientar que a DPU tem tido atuação importante em Pacaraima/RR, cidade por onde entra a maioria dos venezuelanos no Brasil e onde está instalada força tarefa da Operação Acolhida, iniciativa do governo federal para controle e organização do fluxo migratório na fronteira com Venezuela.

O $3^{\circ}$ Informe da Missão Pacaraima, elaborado pela DPU (2020), revela que em 2019, o órgão promoveu o deslocamento constante do total de 52 Defensores Públicos Federais, para atendimento de crianças e adolescentes, com fulcro na Resolução Conjunta, no Município de Pacaraima/RR. Segundo consta, em 2019, foram atendidos 6.085 crianças e adolescentes em especial dificuldade migratória. No segundo semestre de 2019, foram atendidos 3.501 crianças e adolescentes: 1.998 estavam separados; 423 desacompanhados; e 1.080 indocumentados. Desses 423 desacompanhados, cerca de 37 foram encaminhados para acolhimento institucional. Ainda em relação ao segundo semestre de 2019, houve indicação de regularização migratória por meio da residência temporária em 1.483 atendimentos e de solicitação de refúgio em 2.018.

Vê-se, pois, que a Resolução Conjunta - a despeito do problema apontado acima consiste em avanço relevante para a proteção de crianças e adolescentes separados ou desacompanhados, em contexto de migração internacional, no Brasil.

\section{Conclusão}

Conforme se demonstrou, a migração de crianças e adolescentes tem aumentado nos últimos anos, o que exige que sua proteção legal, nesse contexto, seja pensada de maneira a que sejam levadas em consideração suas especiais vulnerabilidades.

No âmbito internacional, verifica-se que a Convenção sobre Direito das Crianças tem vocação de universalidade e, em conjunto com outros instrumentos internacionais - como a Convenção relativa ao Estatuto dos Refugiados - promove proteção suficiente para crianças e adolescentes separados ou desacompanhados no contexto de migração internacional. O Comentário Geral n. 6 do Comitê de Direitos da Criança estabelece diretrizes destinadas aos Estados parte no que tange às obrigações previstas na Convenção e como deve ocorrer sua aplicação para esse grupo vulnerável específico. No Brasil, observa-se que coube à Resolução Conjunta CONANDA/CONARE/CNIg/DPU n. 1/2017 tratar com especificidade sobre os procedimentos de identificação, proteção e representação, para fins de regularização migratória, de crianças e adolescentes separados desacompanhados. À DPU foi concedido papel 
ARCE, Andressa Santana; AMARAL, Ana Paula Martins. Crianças e adolescentes separados ou desacompanhados: uma análise sobre a Resolução Conjunta n. 1/2017 à luz do direito internacional

fundamental nesse processo, na medida em que lhe compete entrevistar a criança ou o adolescente, identificar a proteção mais adequada ao caso e representar a criança ou o adolescente, perante as autoridades competentes, para solicitar sua regularização migratória.

Embora a Resolução Conjunta possa ser considerada como um avanço no que tange à proteção de crianças e adolescentes separados ou desacompanhados, em contexto de migração internacional, no Brasil, não se pode ignorar que a DPU tem pouca abrangência territorial, de modo que finda por se mostrar como insuficiente para os fins a que se destina.

\section{Referências}

AMARAL, A. P. M; COSTA, L. A (não) criminalização das migrações e políticas migratórias no Brasil: do Estatuto do Estrangeiro à nova Lei de Migração. Revista Justiça do Direito, v. 31, n. 2, p. 208-228, maio/ago. 2017. DOI: https://doi.org/10.5335/rjd.v31i2.7147 Disponível em: http://seer.upf.br/index.php/rjd/article/view/7147/4340 Acesso em: 30 jun. 2021.

AMARAL, A. P. M. A proteção da criança em situação de vulnerabilidade no direito internacional. In: FURLAN, V. (org.). Sujeito no direito: história e perspectivas para o século XXI. Curitiba: Editora CRV, 2012.

BRASIL. Conselho Nacional dos Direitos das Criança, Comitê Nacional para Refugiados, Conselho Nacional de Imigração e Defensoria Pública da União. Resolução n. 1 de 9 de agosto de 2017. Estabelece procedimentos de identificação preliminar, atenção e proteção para criança e adolescente desacompanhados ou separados, e dá outras providências Brasília: Diário Oficial da União, 2017a. Disponível em: http://www.in.gov.br/materia/lasset_publisher/Kujrw0TZC2Mb/content/id/19245715/do1-2017-08-18-resolucao-conjuntan-1-de-9-de-agosto-de-2017-19245542 Acesso em: 30 jun. 2021.

BRASIL. Constituição da República Federativa do Brasil de 1988. Brasília: Presidência da República, 2020a. Disponível em: http://www.planalto.gov.br/ccivil_03/constituicao/constituicao.htm Acesso em: 30 jun. 2021.

BRASIL. Decreto n. 9.873 de 27 de junho de 2019. Dispõe sobre o Conselho Nacional de Imigração. [Brasília]: Diário Oficial da União, 2019a. Disponível em: https://portaldeimigracao.mj.gov.br/images/trabalho-estrangeiro/novalegislacao/item/download/DECRETO\%20N\%C2\%BA\%209.873,\%20DE\%2027\%20DE\%20J UNHO\%20DE\%202019.pdf Acesso em: 30 jun. 2021.

BRASIL. Lei Complementar n. 80 de 12 de janeiro de 1994. Organiza a Defensoria Pública da União, do Distrito Federal e dos Territórios e prescreve normas gerais para sua organização nos Estados, e dá outras providências. Brasília: Presidência da República, [2020b]. Disponível em: http://www.planalto.gov.br/ccivil_03/leis/lcp/lcp80.htm Acesso em: 30 jun. 2021.

BRASIL. Lei n. 13.445 de 24 de maio de 2017. Institui a Lei de Migração. Brasília:

Presidência da República, [2017b]. Disponível em:

http://www.planalto.gov.br/ccivil_03/_ato2015-2018/2017/lei/113445.htm Acesso em: 30 jun. 2021. 
BRASIL. Lei n. 8.069 de 13 de julho de 1990. Dispõe sobre o Estatuto da Criança e do Adolescente e dá outras providências. Brasília: Presidência da República, 2019b. Disponível em: http://www.planalto.gov.br/ccivil_03/leis/18069.htm Acesso em: 30 jun. 2021.

BRASIL. Lei n. 8.242 de 12 de outubro de 1991. Cria o Conselho Nacional dos Direitos da Criança e do Adolescente (Conanda) e dá outras providências. Brasília: Presidência da República, [1991?]. Disponível em: http://www.planalto.gov.br/ccivil_03/leis/18242.htm Acesso em: 30 jun. 2021.

BRASIL. Lei n. 9.474 de 22 de julho de 1997. Define mecanismos para a implementação do Estatuto dos Refugiados de 1951, e determina outras providências. Brasília: Presidência da República, [2020c]. Disponível em: http://www.planalto.gov.br/ccivil_03/leis/19474.htm. Acesso em: 30 jun. 2021.

BRASIL. Ministério da Justiça e Segurança Pública. Portaria n. 197 de 6 de março de 2019. Estabelece procedimentos para a tramitação de requerimentos de autorização de residência, registro e emissão da Carteira de Registro Nacional Migratório para a criança ou o adolescente nacional de outro país ou apátrida, desacompanhado ou separado, que se encontre em ponto de controle migratório nas fronteiras brasileiras ou no território nacional. Brasília:

Diário Oficial da União, 2019c. Disponível em: https://www.in.gov.br/materia/-

/asset_publisher/Kujrw0TZC2Mb/content/id/65980921\#: :text=Estabelece\%20procedimentos \%20para\%20a\%20tramita\%C3\%A7\%C3\%A3o,de\%20controle\%20migrat\%C3\%B3rio\%20na s\%20fronteiras Acesso em: 30 jun. 2021.

COLÓQUIO SOBRE PROTEÇÃO INTERNACIONAL DOS REFUGIADOS NA AMÉRICA CENTRAL, MÉXICO E PANAMÁ. Declaração de Cartagena de 1984. [Genebra]: ACNUR, [2001?]. Disponível em: https://www.acnur.org/fileadmin/Documentos/portugues/BD_Legal/Instrumentos_Internacion ais/Declaracao_de_Cartagena.pdf Acesso em: 30 jun. 2021.

COMMITTEE ON THE RIGHTS OF THE CHILD (CRC). General Comment n. 6. [Geneva]: CRC, 2005. Disponível em:

https://www2.ohchr.org/english/bodies/crc/docs/GC6.pdf Acesso em: 30 jun. 2021.

CORTE INTERAMERICANA DE DIREITOS HUMANOS (CIDH). Parecer Consultivo OC-21/14. San José: CIDH, 19 ago. 2014. Disponível em:

http://www.corteidh.or.cr/docs/opiniones/seriea_21_por.pdf Acesso em: 30 jun. 2021.

DEFENSORIA PÚBLICA DA UNIÃO (DPU); ORGANIZACÃO INTERNACIONAL PARA MIGRAÇÃO (OIM). Manual de procedimentos e peças da coordenação de migrações e refúgio da DPU de São Paulo. [Brasília]: DPU, 2018.

DEFENSORIA PÚBLICA DA UNIÃO (DPU). Assistência jurídica integral e gratuita no Brasil: um panorama da atuação da Defensoria Pública da União. 3. ed. Brasília: DPU, 2018.

DEFENSORIA PÚBLICA DA UNIÃO (DPU). Missão Pacaraima: $3^{\circ}$ informativo de atuação. Brasília: DPU, 2020. Disponível em: https://www.dpu.def.br/migracoes-e-refugio Acesso em: 30 jun. 2021. 
ARCE, Andressa Santana; AMARAL, Ana Paula Martins. Crianças e adolescentes separados ou desacompanhados: uma análise sobre a Resolução Conjunta n. 1/2017 à luz do direito internacional

INTERNATIONAL ORGANIZATION FOR MIGRATION (IOM). World migration report 2020. [Geneva]: IOM, 2019. Disponível em:

https://publications.iom.int/system/files/pdf/wmr_2020.pdf Acesso em: 30 jun. 2021.

JUBILUT, L. L.; APOLINÁRIO; S. M. O. A necessidade de proteção internacional no âmbito da migração. Revista Direito GV, São Paulo, n. 6(1), p. 275-294, jan./jun. 2010. Disponível em: http://www.scielo.br/scielo.php?script=sci_arttext\&pid=S1808-24322010000100013 Acesso em 1 maio 2020.

ORGANIZAÇÃO DAS NAÇÕES UNIDAS (ONU). Convenção relativa ao estatuto dos refugiados, de 1951. [Genebra]: ACNUR, [2001?]. Disponível em:

https://www.acnur.org/fileadmin/Documentos/portugues/BDL/Convencao_relativa_ao_Estatu to_dos_Refugiados.pdf Acesso em: 30 jun. 2021.

ORGANIZAÇÃO DAS NAÇÕES UNIDAS (ONU). Convenção sobre os Direitos da Criança. [s.l.]: UNICEF, [2017?]. Disponível em: https://www.unicef.org/brazil/convencaosobre-os-direitos-da-crianca Acesso em: 30 jun. 2021.

SANTOS, I. D. C. A proteção das crianças e adolescentes refugiados no Brasil: a necessidade de políticas públicas de integração. Orientadora: Patrícia Tuma Martins Bertolin. 2018. 2, 279 f. Tese (Doutorado em Direito Político e Econômico) - Universidade Presbiteriana Mackenzie, São Paulo, 2018. Versão eletrônica.

UNITED NATIONS HIGH COMISSIONER FOR REFUGGEES (UNHCR). Global trends: forced displacement in 2019. [Geneva]: UNHCR, 2020. Disponível em: https://www.unhcr.org/statistics/unhcrstats/5ee200e37/unhcr-global-trends-2019.html Acesso em: 30 jun. 2021. 